\title{
Risk Management of Medical Social Work Ethics
}

\author{
Xu Yanfeng \\ Department of Social Work Fudan University, Shanghai, China \\ xuyanfengmaple@foxmail.com
}

\begin{abstract}
Risk Management origins from western industry countries. The thesis takes risk management perspective on medical social work ethics. Firstly, social work ethics are divided into two categories ; Secondly, building the general frame of ethical risk management in medical social work, including risk identification , decision-making, estimation, assessment and monitoring.
\end{abstract} Work

Index Term - Ethical Risk Risk Management Medical Social

\section{I . Introduction}

Medical social work is defined as social workers service the patients and their families to solve psychological and social problems[1]. One of the most important components in medical social work is professional ethic. Social workers who engaged in health care institutions must comply with relevant codes. Hippocrates, the father of medicine, established the classic medical ethics. Medical social worker Pasnau proposed medical social work the ten commandments and etiquette (1985) [2] by integrating the medical ethics into medical social work practice. With the development of profession, especially in Taiwan, Qinyan made the medical social work ethics codes on the base of Taipei Veterans General Hospital[3].The social work ethics by Qin cover the patients and their families (like equal treatment, protecting patient privacy, increasing the client welfare ,et al.), colleagues(cooperating and sharing), and professional development (like do more research) [4].

Risk is defined as uncertainty effects to goals(ISO 31000:2009).Sincethe1990s, a preoccupation with risk and management has engulfed public sector services, including transport ,health, education and social care[5].Currently available data and professional standards suggest that there are a number of key risk areas that should be addressed in an ethics audit in an effort to protect clients and prevent ethics complaints and ethics-related lawsuits[6].Frederic G. Reamer found that the most prominent social work ethical risks are client rights, confidentiality and privacy, informed consent, service delivery, relationship boundaries, conflict of interest,professional instruments, defamatory, supervision, training,counseling, referral, fraud, termination of service and practitioner impairment[6].

Medical social work is a high-risk agency as well as clinical medicine. Therefore, this thesis discusses the ethical risks in medical social work practice and the approaches to manage them properly.

\section{II . Findings}

\section{A. Medical Ethical Risk Events}

The hospital itself is a high-risk health services industry. What kind of risks will happen in medical social work practice? What are the medical social work ethical risks? Let us look at a few cases.

Case1: Lily is a medical social worker in the surgery department for cancer patients and their families. Her client, a 68-year-old elderly people, had a stomach surgery in her department. The doctor said to Lily, the patient was in weak and unstable condition. One day, the patient's daughter requested Lily not to tell her father that he had a cancer. She said if her father knew the diagnosis, he will not be able to withstand such a blow. She also please Lily to ask the doctor not to tell her father the fact[7].

Questions: What should Lily do? Whether tell the client(the father) the fact or not? Whether please the doctor or not? What's the results ?In fact, the social work is troubled in the dilemma which maybe lead to harm and high risk.

Case2: The social worker Ximo had sexual relations with his sick client Bella. Bella has a personality disorder. In consultation, Bella engendered empathy to Ximo. They spent the weekend together and had sex. Ultimately Ximo was prosecuted by Stanford Hospital Ethics Committee and deserved the punishment[8]( summarized by the author).

Questions: Which behaviors are illegal at any time? Which behaviors are not allowed in any case?

Case3: Three different kidney patients. The first one is a married woman, and has two sons. She is inflammation of the urethra infection that her kidneys gradually lose function. She feels depressed and loses interest in life. Her life must rely on dialysis. The second is a 55-year-old male, whose has been in trouble for the past four years. Because of his unsuccessful transplant surgery ,he stayed at home to receive the necessary treatment. He masters how to use dialysis machine, so he can live a normal life in the present condition. But the dialysis machine does not work recently, the only company to repair the manufacture is too far and it would take at least two or three days to send it back when he can not wait so long. The third one is a 24-year-old female student, who mistakenly ate poisonous mushrooms, led to loss of kidney function. Because the serious situation, she needs immediate dialysis. If dialysis, the probability of recovery is quite high..

Questions: What will you do as the medical social worker? Who should get the limited resource? How to allocate the resources between several clients?

In a word, all these cases are the ethical events which social workers met during their work. If coping with it improperly, it will lead to unimaginable consequences.

\section{B. Risk Categories in Medical Social Work}

What is the risk of social work ethics? There is no precise 
definition in academic field. In this study the definition of social work ethical risk is social workers made ethical decisions which have uncertainty consequences and have negative impacts on clients. According to the causes of social work ethical risks, it can be divided into two categories. One is the risk caused by acts of commission or misfeasance, the other one is caused by acts of omission or nonfeasance[2], as in table I.

TABLE I Social Work Ethical Risk

(according to its different causes)

\begin{tabular}{|c|c|}
\hline Risk Categories & Risk Events ( mainly about ethical risks to clients ) \\
\hline \multirow{8}{*}{$\begin{array}{l}\text { The ethical } \\
\text { risks caused by } \\
\text { acts of } \\
\text { commission or } \\
\text { misfeasance or } \\
\text { malfeasance }\end{array}$} & Inappropriate treatment to client \\
\hline & Sexual misconduct \\
\hline & Violation of confidence \\
\hline & Violation of self-determination \\
\hline & The allocation of limited resources \\
\hline & Assault \\
\hline & Close the case inappropriately \\
\hline & The false colleagues audit \\
\hline \multirow{6}{*}{$\begin{array}{l}\text { The ethical } \\
\text { risks caused by } \\
\text { acts of } \\
\text { omission or } \\
\text { nonfeasance }\end{array}$} & Disclose the client's secret without informed consent \\
\hline & Failed to prevent the suicide of client \\
\hline & Be absent when the client needs service \\
\hline & Failed to prevent a third party injured \\
\hline & Failed to properly supervise the client \\
\hline & Failed to referral client to experts \\
\hline
\end{tabular}

As shown in table II, risks can be divided into five categories on the basis of the risk objects, that is, ethical risk to clients, to colleagues, to agencies, to professional and to society.

TABLE II Social Work Ethical Risk

(according to its different risk objects)

\begin{tabular}{|l|l|}
\hline \multicolumn{2}{|l}{ (according to its different risk objects) } \\
$\begin{array}{l}\text { Risk } \\
\text { Categories }\end{array}$ & Risk Events [9] \\
\hline $\begin{array}{l}\text { Ethical risk to } \\
\text { clients }\end{array}$ & $\begin{array}{l}\text { Level of confidentiality, the degree of self- } \\
\text { determination, limited resource allocation }\end{array}$ \\
\hline $\begin{array}{l}\text { Ethical risk to } \\
\text { colleagues }\end{array}$ & $\begin{array}{l}\text { Whether workers should denounce colleagues } \\
\text { and superiors' unethical behaviors }\end{array}$ \\
\hline $\begin{array}{l}\text { Ethical risk to } \\
\text { agencies }\end{array}$ & $\begin{array}{l}\text { The contradiction between client needs and } \\
\text { bureaucracy }\end{array}$ \\
\hline $\begin{array}{l}\text { Ethical risk to } \\
\text { profession }\end{array}$ & $\begin{array}{l}\text { The contradictions between professional ethics } \\
\text { and individual ethical }\end{array}$ \\
\hline $\begin{array}{l}\text { Ethical risk to } \\
\text { society }\end{array}$ & $\begin{array}{l}\text { The contradictions between disadvantaged } \\
\text { individuals and social system }\end{array}$ \\
\hline
\end{tabular}

In summary, the social work ethical risks consist of risks to the client, colleagues, institutions, profession as well as social workers themselves. The generation of these ethical risks comes from improper practice of social workers or inobservance of professional obligations. This study aims at exploring the social work ethical risk management in medical social work practice .

\section{Medical Social Work Ethics Risk Management}

In my opinion, medical social work ethic risk is defined as medical social workers discover and confirm the risk events, which are harmful to clients, social workers and institutions.

Risk management is derived from Banking Industry in the 1930s. In the field of social work, Frederic G. Reamer suggested that the purpose of discussion about social work risk is to explore the nature and forms of social work error and possible constructive responses to it that (a) protect clients, (b) minimize risk to social workers, (c) prevent future error, and (d) adhere to prevailing ethical standards in the profession[10].

According to ISO 31000: 2009 standard, risk management is defined as "the coordination activities of an organization to command and control of the risks taken." General risk management process includes risk identification, risk estimation, risk assessment, risk decision-making and risk monitoring[11].

\section{Risk Identification}

According to the approaches of clinical risk identification and the disciplines of social work, I come up with ethical risk identification methods as follows. There are two paths, one is relying on professional judgments by medical social workers, which depends on personal experience and the sensitivity to ethical risks. In addition, it is a great challenge for young social workers and their supervisors. The other is to establish ethical risk identification system, in which there exist a large number of cases to help social workers to identify risks. In order to be better, it is necessary to identify risks with two approaches hand in hand.

Firstly, establishing the medical social work ethical risk identification electronic system. In this system, medical social workers can find the best solution to different ethical risk events. If social workers meet dilemma, they can log in the system and search what they need.

Secondly, establishing the informal ethical risk identification system, which exchanges working experience with co-workers, supervisor and medical personnel regularly.

Thirdly, having courses like ethical risk management during college; Besides, social workers attend trainings to enhance professional sensitivity at their working time.

Fourthly, systematic researches and reports, which are done by National Association of Social Workers and other related departments, supply to medical social workers .

Finally, to establish the Medical Social Work Ethics Risk Identification Committee, which provides guidance and help for clinical practice. 


\section{E. Risk Estimation and Risk Assessment}

When making risk estimation and assessment, we need to answer four interrelated questions: how bad are things? How common are things? What will happen? Whether need to take actions or not? [12] There are two steps in risk estimates and risk assessment. First step is to confirm the related person and the effects on them. Second is to evaluate the risks and consider whether need to take actions.

Ethical risk assessment is similar to social work ethical choice model , however, the ethical choice model only provides a general method to ethical dilemma. It has not tell the probability of risk precisely. Therefore, ethics risk assessment provides a possibility to present the probability of the risk quantitatively.

To begin with, medical social workers, researchers and institutions establish risk maps and risk matrix tables, which are based on amounts of empirical experience. It makes ethical risk estimableness to get rid of personal experience and intuition. In the meantime, it helps to classify and quantized the risk description. Moreover, the abscissa of risk matrix table shows the degree of risk impact, while the vertical axis presents the possibility of risk with five dimensions. In addition, developing different risk matrix to different people.

In the second place, to determine whether intervene the events, take further security measures or not. The approaches in Reamer's ethical dilemma decision-making model could guide social workers to assess risk when faced with ethical risk event. Reamer's method requires identify all possible action plan and its positive and negative potential features. The method is to thoroughly research on the reasons for and against the action. This study should consider ethical theories, rules, principles, codes of ethics, legal principles, the principle of social practice and confliction between professional and personal values. The next step is to counsel experts or colleagues[13]. In conclusion, medical social workers can take the above steps to make the ethical risk assessment.

\section{F. Risk Decision}

Risk aversion is one of risk response methods. In the field of medical social work, it means that social workers avoid the risks caused by improper behaviors during professional services. However, it will lead to the results that nobody serves the riskiest but neediest client. For this reason, I am for risk prevention, instead of risk aversion. I suggest six points in the following.

First, medical social workers should sign a care partnership agreement with clients to prevent risk events and reduce risk loss.

Second, building up risk investigation team. The team is led by senior staff, including managers, project leaders, supervisors and risk manage specialists. At the same time, the team has responsibility to give feedbacks to all frontline social workers.

Third, setting up risk disclosure group, whose duty is to inform patients, their families and doctors about risk events in the premise of ethical permission.
Fourth, the good use of the documents, including the allowed recordings. Documents play important roles in six aspects, namely, assessment and plan, service delivery, service continuity and coordination, supervision, service evaluation and accountability to clients, institutions, other parties, courts[14][15][16]. Making full use of documents, medical social workers can reduce the number of unnecessary ethical risks.

What is more, to sign the ethical risk prevention agreement with clients. let the clients consent the possible risk events and solutions.

In addition, if the risk occurred, medical social workers should reduce the loss of risk on the basis of the maximizing interests of clients.

\section{G. Risk Monitoring}

Risk monitoring is defined as tracking, identifying and monitoring risks in the process of risk management, and evaluating the effectiveness of the reducing risk measures.

Risk Monitoring is similar to Reamer's ethical choice model. Making decision and recording the process of decisions ,tracking and assessing the results. When monitoring ethical risk, social workers need to reflect their own services. To reduce the ethical risk of clients and their families, it also requires managers to follow up supervision and evaluation.

\section{III . Discussion}

The article tries to develop the approach in social work ethical risk management by using the experience of other disciplines for reference. If all above could come true, it will help to reduce risk in social work practice to some extent. Only more social workers and researchers making joint efforts on risk management could protect the clients, social workers, institutions and society better.

\section{Acknowledgment}

I acknowledge gratefully the help from my tutor Zhao Fang and my friends during this time. And thank all the people who give me a hand.

\section{References}

[1] Liu Jitong,Medical Social Work Introduction,Beijing: Higher Education Press, 2008

[2] David Guttmann, Hsiu-Lan Shelley Tien Peng Mengyao translation, social work ethics: learn the rich culture Co., Ltd., 2011

[3] Qin Yan, medical social work [2], London: Sage Books, 1996

[4] Chen Zhonglin, Huang Xiaoyan with social work values and ethics, Beijing: Higher Education Press, 2011

[5] Geraldine Macdonald* and Kenneth Macdonald, Safeguarding: A Case for Intelligent Risk Management , British Journal of Social Work (2010) $40,1174-11$

[6] Frederic G. Reamer , The Social Work Ethics Audit: A RiskManagement Strategy, Social Work / Volume 45, Number 4 / July 2000

[7] David Gutmann, Ethics in Social Work-A Context of Caring, 2006, The Haworth Press

[8] Irvin D. Yalom, Lu Mi translation, Lies on Treatment Chair, Beijing: Mechanical Industry Press, 2012

[9] Gu Donghui, Introduction to Social Work, Shanghai: Fudan University Press, 2010 
[10] Frederic G. Reamer, Social Workers' Management of Error : Ethical and Risk Management Issues, FAMILIES IN SOCIETY | Volume 89, No. 1

[11] Wang Zhouwei, Risk Management, Beijing: Mechanical Industry Press, 2012

[12] Li Qinggong,Clinical Risk Management, Beijing: People's Health Publishing House, 2009

[13] David Guttmann, Hsiu-Lan Shelley Tien Peng Mengyao translation, social work ethics: learn the rich culture Co., Ltd., 2011
[14] Kagle, J. (1995a). Recording. In R. Edwards (Ed.-in-Chief), Encyclopedia of social work (19th ed., Vol. 3, pp.2027-2033). Washington, DC: NASW Press.

[15] Luepker, E., \& Norton, L. (2002). Record keeping in psychotherapy and counseling: Protecting confidentiality and the professional relationship. New York: Brunner-Rout ledge.

[16] Reamer, F. (2003). Social work malpractice and liability: Strategies for prevention (2nd ed.). New York: Columbia University Press. 